\title{
La producción de banano bajo el sistema de comercio justo: un análisis del caso ecuatoriano
}

\section{Banana production under the fair-trade system: an analysis of the Ecuadorian case}

\author{
Juan Borja ${ }^{1}$ \\ ${ }^{1}$ Universidad Central del Ecuador. Facultad de Ciencias Agrícolas. Carrera de Ingeniería Agronómica. Jerónimo Leiton y Av. La Gasca s/n. \\ Ciudadela Universitaria. Quito. 170521. Ecuador
}

\begin{abstract}
Resumen
Este trabajo analiza el comercio justo de banano en Ecuador. Esta modalidad de comercialización ha permitido a los productores campesinos organizados obtener mejores ingresos económicos que los campesinos que comercializan la fruta a través del sistema tradicional. El comercio justo está también asociado con la disminución en la aplicación de insumos y el uso de tecnologías que causan menor impacto al ambiente. Las potencialidades y limitaciones de la comercialización alternativa se discuten a través del texto.
\end{abstract}

Palabras clave: comercio justo, intercambio desigual, comercio internacional, banano, Ecuador.

\begin{abstract}
This work analyzes banana fair-trade in Ecuador. By means of this system, organized small-scale farmers were able to improve their earning compared to those involved in traditional trade. Additionally, fair-trade is also associated with a reduction in the application of inputs and the use of cleaner technologies which have a lower environmental impact. The potential and limitations of the fair-trade system is also discussed throughout the text.
\end{abstract}

Keywords: fair-trade, unbalanced exchange, international trade, banana, Ecuador.

\section{Introducción}

La nueva crisis económica que se inicia en este período en el país por la baja en los precios del petróleo hace que las teorías relacionadas con la dependencia, el intercambio desigual y el deterioro en los términos de intercambio recobren vigencia para explicar las causas de estos problemas.

Desde la óptica del pensamiento crítico, es innegable que el comercio internacional está caracterizado por una relación inequitativa entre los países industrializados y los países productores de materias primas y alimentos, y que el problema del intercambio comercial no puede ser abordado solo desde la simple arista técnica.
En el contexto de las situaciones provocadas por las condiciones de desarrollo desigual prevalentes en el mundo, surgen inquietudes como las siguientes: ¿puede existir comercio justo en las condiciones descritas?, ¿la poca experiencia acumulada con el comercio justo en algunos productos puede ser suficiente para revertir el histórico desbalance de intercambio que han sufrido los bienes primarios en relación a los bienes industrializados?, ¿garantizan el comercio justo los tratados de libre comercio, sean estos a nivel de la Organización Mundial del Comercio o de país a país, cuando existen diferencias abismales en el desarrollo económico entre los mismos?

Estas son las preguntas de investigación que se abordan en el presente trabajo, el cual toma como 
estudio de caso la comercialización del banano, producto que históricamente ha tenido un gran peso en la economía del país y que ante la actual crisis del petróleo se convierte en una fuente alternativa de divisas para sostener la dolarización.

\section{Descripción del problema}

Los productores de banano desempeñan doble papel en sus actividades, por un lado son vendedores del agro-producto $y$, por otro, son compradores de bienes productivos e insumos provenientes de los países industrializados. Esta situación genera un proceso de deterioro de los "términos de intercambio", dado que los precios de los productos manufacturados tienden a crecer más rápidamente que los de los productos primarios (Cyper \& Dietz, 2004; Prebisch, 1996).

La producción bananera está en manos de la economía familiar campesina (EFC) que participa con el $85 \%$ de la producción nacional, sin embargo, debido a la estructura agraria de este sector, se produce la transferencia del valor generado por la EFC a empresas exportadoras de la fruta que obtienen un mayor beneficio, éstas a su vez ceden una parte del beneficio extra a las comercializadoras de banano de los países importadores. Por otro lado, los precios de los bienes e insumos necesarios para la producción, especialmente pesticidas, maquinaria, avionetas y equipos de aspersión, presentan mayores incrementos en relación a los precios de la fruta lo que aumenta los costos de producción y disminuye los ingresos netos de la EFC.

El intercambio desigual es el resultado de las diferencias en el mercado de trabajo entre los países desarrollados y los países en vías de desarrollo (Amin, 1975). Este autor señala que estas diferencias hacen que los incrementos de productividad se expresen en mayores remuneraciones para los factores productivos nacionales de los países desarrollados, mientras que en los países menos desarrollados, estos incrementos de productividad se transfieren al resto del mundo en forma de precios menores. Este sistema de intercambio inequitativo afecta a la dolarización en el Ecuador, puesto que produce un desbalance entre las importaciones y exportaciones y un déficit en la balanza comercial.

Organizaciones privadas ligadas a los países desarrollados, especialmente organizaciones no gubernamentales, toman conciencia de la desigualdad de las relaciones del comercio mundial y desarrollan la modalidad comercial de "buena voluntad" también cono- cida como "comercio justo", la cual busca reconocer mejores precios, en relación al mercado común, a los agricultores de los países de la periferia que producen alimentos con técnicas más amigables con el ambiente y con respeto a las relaciones sociales y laborales.

El comercio justo puede beneficiar económicamente al agricultor dado que respeta los precios pagados al productor independientemente sin importar las variaciones de la oferta y la demanda del mercado. "El precio pagado a los productores de las organizaciones campesinas vinculadas al comercio justo siempre es, como mínimo, 20\% superior al precio pagado por los intermediarios del mercado convencional" (Doppler \& González, 2007).

El comercio justo, entonces, se convierte en una alternativa que si bien no rompe con las causas estructurales de los problemas de comercialización, permite que los productores que comercializan sus materias primas a través de este canal alternativo reciban un mejor precio y con ello un reconocimiento a las formas de producción social en el campo, las cuales están estrechamente ligadas a la AFC.

En los últimos cinco años, Ecuador comercializó 559 millones de dólares bajo la normativa de comercio justo, beneficiando a pequeños productores, cooperativas, artesanos y pequeñas y medianas empresas del país. Las exportaciones en la modalidad de comercio justo se incrementaron de US \$ 62,1 millones en 2007 a US \$ 168,6 millones en 2011, lo que significa un incremento de 171,4\% (ANDES, 2012). De acuerdo a la misma fuente, los principales productos que se comercializaron bajo esta modalidad fueron cacao con el $57 \%$ de las exportaciones totales de este producto, banano con el 5,93\% y café en grano con el 3,73\%.

\section{El sector bananero ecuatoriano}

Durante la primera etapa del país como república se consolidan las bases para la modalidad de acumulación primaria bienes que se basa en la exportación de materias primas y en la importación de los insumos y maquinaria para producirlos, así como de bienes suntuarios para el disfrute de la clase dominante. El mismo autor manifiesta que la producción de banano se consolida en la década de los años cincuenta, pasando a ser el primer producto de exportación del país en sustitución del cacao y el arroz. A diferencia del cacao, el banano amplió las fronteras agrícolas con el ingreso a la producción de fincas pequeñas y medianas. 
En el año 2012, el sector bananero ecuatoriano exportó 284,6 millones de cajas, con ingresos por US $\$ 2.235$ millones y generó más de US $\$ 90$ millones en impuestos fiscales, constituyéndose en uno de los principales contribuyentes al erario nacional. Estas cifras representan el $32 \%$ del comercio mundial de banano (US \$ 7 mil millones), el 3,84\% del PIB corriente total, el $50 \%$ del PIB corriente agrícola y el $20 \%$ de las exportaciones privadas del país (Banco Central del Ecuador, 2012).

Según la Asociación Ecuatoriana de Exportadores de Banano (AEBE, 2015), en el país existen 6.950 Unidades Productivas Agropecuarias (UPAs) dedicadas a la producción de banano, de éstas, 3.705 tienen superficies comprendidas entre 1 y 10 ha, 2.265 abarcan superficies entre 11 y 50 hectáreas y 980 productores cuentan con superficies mayores a 50 hectáreas. Es decir, los pequeños y medianos productores representan el $85 \%$ del total de productores, pero en contraste controlan solamente el $38 \%$ de la superficie cultivada del banano en el país.

El mercado del banano en el Ecuador se caracteriza por el oligopsonio de13 empresas exportadoras que concentran los mayores volúmenes de ventas, las cinco empresas más importantes son UBESA, PACIFIC CROWN FRUIT, Bananera Continental, Fruitstylelife y Reybanpac, que en conjunto suman el $40 \%$ de las exportaciones. Ante este panorama, han surgido mecanismos de comercio alternativos que buscan garantizar el equilibrio entre conciencia ambiental, justicia social y rédito económico. Uno de los mecanismos de comercio más paradigmático es el comercio justo (SIPAE, 2010).

\section{Descripción de la cadena de comer- cialización del banano en un esquema de comercio justo}

\subsection{Costos de producción}

Los costos de producción de banano bajo el esquema de comercio justo ascienden a US $\$ 6,25$ por caja de $18,5 \mathrm{~kg}$ de fruta y el productor recibe US $\$ 7$ por caja, quedándole un beneficio de US $\$ 0,75$. En el esquema de comercio convencional los costos de producción son de US $\$ 4,80$ por caja y el precio pagado al productor es de US $\$ 5,50$, quedando una ganancia para el productor de US \$0,70 (Velasteguí, 2014).

Cabe mencionar que los productores que comercializan en el sistema alternativo también reci- ben ingresos adicionales al final del año de parte de las comercializadoras con el objetivo de que estos recursos fortalezcan las organizaciones y se inviertan en proyectos sociales, ambientales y de salud. Estos beneficios no existen en el sistema tradicional de comercio. En este sentido, UROCAL (Unión Regional de Organizaciones Campesinas del Litoral) recibió en el 2013 US \$ 200.940 de la Organización Nuevo Mundo por este concepto (Velasteguí, 2014).

\subsection{Insumos}

Las prácticas agrícolas de los productores ligados al comercio justo son amigables con el ambiente y la salud humana. Se basan en un menor uso de insumos químicos lo que reduce los costos de producción. La producción media para el agricultor de comercio justo es de 1.400 cajas/ha/año, frente a las 1.800 cajas/ ha/año del productor convencional. La diferencia de productividad está relacionada con el hecho de que la agricultura convencional se basa en la utilización intensiva de insumos químicos que generan problemas ambientales y de salud (Velasteguí, 2014).

En el caso de los agricultores inmersos en el comercio convencional, la compra de insumos representa el $25 \%$ de los costos totales de producción, mientras que para los productores de comercio justo solamente es de 19\%. Según el Banco Mundial (2013), el precio de la tonelada métrica de úrea, principal fertilizante utilizado en el cultivo de banano, se incrementó de US \$ 250 a US \$ 340 (36\%) en el período 2008 a 2013, mientras que la tonelada métrica de banano pasó de US \$ 860 a US \$ 881 (2,44\%) en el mismo período.

Tomando solamente en cuenta el incremento de precio de la úrea, insumo básico para la producción de banano, en relación al precio del banano, parecería que la teoría del deterioro de los términos de intercambio se confirma, sin embargo, para confirmar la regla se hace necesario un estudio detallado del comportamiento de los otros insumos importados necesarios para la producción de la fruta. Es importante mencionar que las dos más grandes empresas productoras de úrea del mundo son las transnacionales AGRIUM INC., con sede en Canadá, y REPSOL de capital español.

\subsection{Mano de obra}

Las pequeñas UPAs que tienen hasta 5 hectáreas de superficie y que están ligadas al comercio justo generan entre 1,1 y 1,2 puestos de trabajo/ha, mientras que la gran empresa ligada al comercio tradicional, que 
produce en superficies mayores a 200 ha, solamente emplea entre 0,55 y 0,6 trabajadores/ha (Cepeda, 2009).

En el caso de los agricultores ligados al comercio justo, la mano de obra representa el 19\% del costo total de producción que asciende a US $\$ 8.760$, mientras que en los agricultores del sistema convencional la mano de obra representa el $54 \%$ de los US $\$ 8.640$ de costo total de producción (Velasteguí, 2014).

\subsection{Comercialización}

El proceso de comercialización de los agricultores que participan en el programa de comercio justo de banano se inicia con el acopio de la fruta en los locales de las asociaciones de productores donde se empaca y coloca en contenedores que serán llevados al puerto marítimo. Luego, las organizaciones ligadas al proceso se encargan del transporte marítimo, la maduración y la entrega en las tiendas de comercio justo en país de destino. Finalmente, las tiendas de comercio justo venden el producto al consumidor, último eslabón de la cadena.

La cadena es más larga en el caso del comercio convencional, puesto que existen intermediarios que se encargan de la exportación de la fruta. El número de exportadores es reducido, lo que les otorga discrecionalidad para pagar precios más bajos que los oficiales a los productores.

\section{Referencias}

AEBE. (2015). Estadísticas de la producción de banano. Guayaquil, Ecuador: AEBE.

Amin, S. (1975). La acumulación a escala mundial. Buenos Aires, Argentina: Siglo XXI.

ANDES. (2012). Ecuador prepara un encuentro internacional de comercio justo el 17 de octubre del 2012 en Cuenca. Obtenido de: http://www. andes.info.ec/es/econom\%C3\%ADa/7505.html

Banco Central del Ecuador. (2012). Indicadores económicos. Quito, Ecuador: BCE.

Cepeda, D. (2009). Agroeconomía y rendimiento de sistemas de producción de banano en Ecuador. (Tesis doctoral). Agro Paris Tech, Paris.

Cypher, J., \& Dietz, J. (2004). The process of economic development. Londres, Inglaterra: Routeledge.
Comentarios finales y recomendaciones para políticas públicas.

Este artículo ha analizado las potencialidades y limitaciones del comercio justo de banano tomando como ejemplo el estudio de caso de los pequeños productores ecuatorianos. En base a las normas legales y a la realidad descrita en este artículo se plantean las siguientes recomendaciones:

Si bien es necesario fomentar la organización de los pequeños y medianos campesinos como estrategia para promover su inserción en el esquema de comercio, esta inserción puede catalizarse mediante el fortalecimiento de la Coordinadora Ecuatoriana de Comercio Justo.

En el contexto del cambio de la matriz productiva y del fortalecimiento del comercio justo, sería pertinente la creación de empresas estatales orientadas a la producción de insumos genéricos a fin de disminuir las importaciones que, como se ha demostrado en este estudio, representan una importante fracción de los costos totales de producción. En este mismo sentido, la firma de convenios con universidades para el desarrollo de tecnologías de producción limpia, adaptadas a la realidad local, sería de gran ayuda para incrementar la productividad y reducir el nivel de dependencia de los productores de insumos comerciales convencionales.

Doppler, F., \& González, A. (2007). El comercio justo: entre la institucionalización y la confianza. Problemas de Desarrollo, 38 (149), 181-202.

Prebisch, R. (1996). El desarrollo económico de la América Latina y algunos de sus principales problemas. Santiago, Chile: CEPAL.

SIPAE. (2010). Agroindustria y soberanía alimentaria. Hacia una ley de agroindustria y empleo agrícola. Quito, Ecuador: SIPAE.

Velasteguí, A. (2014). Analisis comparativo de los beneficios monetarios y no monetarios de productores bananeros vinculados o no al comercio justo. (Tesis Ingeniero Agrónomo). Universidad Central del Ecuador, Quito, Ecuador. 